\title{
Sobre paisagem e representação
}

\section{On landscape and representation}

\author{
Prof ${ }^{\mathrm{a}} \mathrm{Dr}^{\mathrm{a}}$ Ligia Saramago \\ ligiasaramago@gmail.com \\ PUC - RJ
}

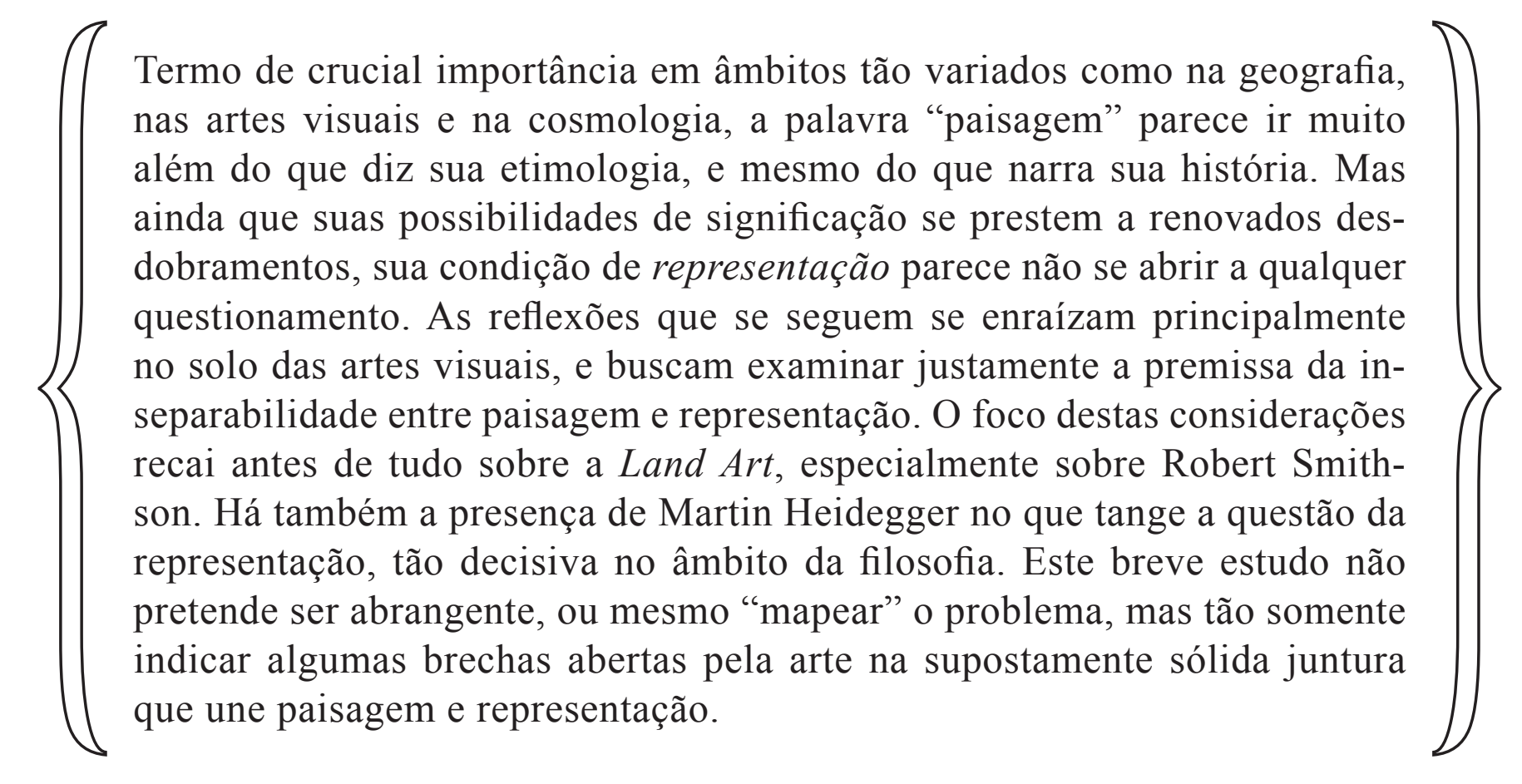

PALAVRAS-CHAVE Paisagem; representação; Land Art; Martin Heidegger

As a fundamental term in areas as diverse as geography, visual arts and cosmology, the word 'landscape' seems to go far beyond its etymology and its history. Although its possible meanings allow new unfoldings, its representational status does not seem subjected to any questioning. Rooted in the visual arts, the present reflexions examine the presupposed inseparability between landscape and representation. These considerations focus primarily on Land Art, especially on the work of Robert Smithson. In order to tackle the issue of representation, I am also making use of Martin Heidegger's seminal philosophical ideas. This brief study is not intended to be comprehensive or even to "map" the problem. It aims rather to point out some loopholes open by art in what is assumed to be a solid bond between landscape and representation.

KEYWORDS Landscape ; representation; Land Art ; Martin Heidegger 
Talvez se possa argumentar que não há sentido em se falar das relações entre paisagem e representação, uma vez que a própria definição de "paisagem" já implica uma forma bastante específica de representação. Termo de crucial importância em âmbitos tão variados como na geografia, nas artes visuais e na cosmologia, por exemplo, a palavra "paisagem" parece ir muito além do que diz sua etimologia, e mesmo do que conta sua história. Mas ainda que suas possibilidades de significação se desdobrem e se transformem de tempos em tempos, ainda que o sentido de paisagem se preste às mais variadas circunstâncias, sua condição de representação parece não se abrir a qualquer questionamento. Isto porque a paisagem jamais se encontra em estado puro, anterior a um sujeito que a conceba como uma "leitura", como "interpretação" de um território ou da própria "natureza".

As reflexões que se seguem se enraízam principalmente no solo das artes visuais, e buscam examinar justamente esta premissa da inseparabilidade entre o conceito de paisagem e a representação. Não se trata aqui de percorrer a história da arte, iluminando os momentos em que a pintura de paisagem atingiu suas mais altas possibilidades, ou de comparar as representações produzidas por artistas e geógrafos. De fato, poucos artistas são mencionados, recaindo o foco destas considerações principalmente sobre a Land Art. Há também a presença de Martin Heidegger no que tange a questão da representação, tão decisiva no âmbito da filosofia. Como ficará claro, este breve estudo não pretende ser abrangente, ou mesmo "mapear" o problema, mas tão somente indicar algumas brechas abertas pela arte na supostamente sólida juntura que une paisagem e representação.

\section{Imagens do Mundo}

Sabemos que o desejo de registro das feições da Terra e de seus arredores, bem como a necessidade de mapeamento dos territórios marcou, desde sempre, o estar do homem no mundo e, em muitos sentidos, este desejo acabou por aproximar o artista e o geógrafo. Tal proximidade alcança expressão, antes de tudo, na noção mesma de paisagem. A propósito desta última, ou do desejo de aprofundar sua compreensão, a ideia de representação será aqui tomada como fio condutor destas considerações, bem como a recusa da representação por algumas das mais expressivas vertentes da arte contemporânea que fizeram da terra o foco de suas criações. 
As noções de mundo e de representação, ou antes, a produção de representações do mundo em seus aspectos visíveis, constituem questões que vêm ocupando tanto geógrafos, como artistas e filósofos desde longa data. Tais representações jamais são imparciais ou neutras, quer se consideradas no âmbito das ciências, da filosofia ou naquele das artes. Segundo Heidegger, para que qualquer representação se faça possível, é necessário que aquilo que é representado tenha se tornado, antes, disponível para o representar. Este tornar algo "disponível", e, no caso, o mundo mesmo, foi pensado por Heidegger em uma conferência proferida em 1938, intitulada O tempo da imagem do mundo, onde o autor busca identificar os fundamentos da imagem moderna de mundo. Alguns aspectos do que foi então colocado por Heidegger devem ser considerados aqui antes de adentrarmos nossa questão.

Um dos pontos centrais do argumento de Heidegger é o que diz respeito à formação da subjetividade moderna, processo pelo qual o homem teria se instituído como o fundamento sobre o qual qualquer compreensão dos entes poderia se dar, assumindo-se como referência para toda e qualquer valoração destes entes. Se por "mundo" não se deve compreender apenas a natureza, em seu sentido planetário, mas sim os entes em sua totalidade, numa confluência de natureza e história, o significado da expressão "imagem do mundo" tampouco se resume a algo da ordem de um desenho, ou de uma narrativa. A possibilidade mesma da produção de imagens do mundo pressupõe, antes de tudo, que o mundo possa ser posto diante de nós e para nós, como objeto perante um sujeito. Onde o mundo se torna imagem, diz Heidegger, a totalidade dos entes é trazida pelo homem para diante de si num sentido que ele define como decisivo, e afirma:

Imagem do mundo, compreendida essencialmente, não quer, por isso, dizer uma imagem que se faz do mundo, mas o mundo concebido como imagem. O ente na totalidade é agora tomado de tal modo que só é algo que é, na medida em que é posto pelo homem representador-elaborador. Onde se chega à imagem do mundo, cumpre-se uma decisão essencial sobre o ente na totalidade. (HEIDEGGER, 1998, p.112)

A expressão "imagem do mundo moderna" diz, segundo Heidegger, duas vezes a mesma coisa, uma vez que o próprio conceber do mundo como imagem é, em si, um dos fenômenos que marcam a era moderna. Não se trata, portanto, 
da transição de uma suposta imagem de mundo antiga ou medieval para outra moderna: a essência da modernidade, diz ele, "é que o mundo se torne, em geral, imagem". O mundo concebido como imagem envolve uma dupla operação: em primeiro lugar, que o homem, o ser-no-mundo, a existência em sua unidade essencial com o mundo, tenha concebido a possibilidade de tornar objeto o que era aparentemente "inobjetivável": o âmbito mesmo de seu existir e fonte de toda e qualquer compreensão possível. Em segundo lugar, que esta totalidade, agora objetivada, se encontre disposta e disponível perante ele que, enquanto sujeito, se assume como aquele que dá a medida, como o fundamento último para suas representações. "Que o mundo se torne imagem e que o homem dentro do ente, se torne sobjectum", diz Heidegger, "é um e o mesmo processo". E mais adiante completa: "O processo fundamental da modernidade é a conquista do mundo como imagem".

É importante sublinhar, como já foi dito aqui, que a palavra "imagem", no sentido que Heidegger the confere, não significa literalmente uma imagem, em um sentido gráfico. "Imagem", para ele, diz representação mental, como uma objetivação criadora de "visões de mundo", ou de "mundividências", como ele as designou. Contudo, mesmo despindo a expressão "imagens do mundo" de conotações pictóricas, é notório o fato de que o que costumamos chamar de início da modernidade - os séculos XV, XVI e especialmente o século XVII foi marcado por uma verdadeira explosão no que tange a criação de imagens do mundo, concebidas também num sentido estritamente pictórico, não apenas por parte da arte, mas, igualmente, no âmbito científico, como nos da geografia e da cosmologia, por exemplo. Também nestes campos se afirma a presença de um sujeito que se coloca perante o mundo, trazendo-o para diante de si e gerando, a partir daí, "mundividências", ou imagens do mundo.

\section{O Atelier Terrestre}

A proximidade entre a cartografia e as representações de paisagens pela pintura no início da modernidade foi tematizada por Jean-Marc Besse em seu ensaio A Terra como Paisagem: Brueghel e a Geografia, onde ele destaca como um evento bastante significativo o fato de, no século XVI, terem surgido e se desenvolvido as ideias de "paisagem do mundo" e de "uma nova representação cartográfica do ecúmeno (ou, como dizem os latinos, da orbis terrarum)". (BESSE, 2000, p.23) Tal encontro, expresso na noção de "paisagem do mundo", significa que a noção mesma de paisagem começa a romper os limites do que é particular, 
ou regional, e estabelece um novo patamar de relações, saindo de uma escala local para relacionar-se com o global, com o que está para além do horizonte.

Segundo Besse, a pintura de Brueghel expressaria este sentido de "paisagens do mundo" deixando ver um aspecto bastante próprio deste momento: o caráter distanciado e contemplativo do olhar que se volta para a Terra. Esta é vista do alto, por alguém que se afastou para melhor apreciar o espetáculo. Besse exprime esta situação nos seguintes termos:

\begin{abstract}
Mas o que é a Terra dentro deste teatro? E como ela é percebida? Sublinhemos este ponto: a Terra, no mapa e na pintura de paisagem que a representam, torna-se um objeto para um sujeito que é o seu espectador, diferentemente do mapa medieval, que conta uma história, e que, mais precisamente, insere a Terra, e o indivíduo que observa sua imagem, no discurso, a um só tempo físico e teológico, da Criação do mundo. (BESSE, 2000, p.26)
\end{abstract}

Besse aponta ainda para o fato de que a conexão entre a cartografia e a experiência paisagística não se consuma apenas por uma simples afinidade de "conteúdos", mas igualmente "no plano de um dispositivo formal de percepção e de pensamento, estruturado pela relação sujeito-objeto". (BESSE, 2000, p.30)

Esta questão foi também extensamente tratada por Edward Casey em sua obra Representing Place e, segundo o autor, sabemos que de forma alguma é acidental que a cartografia e a pintura de paisagem tenham atingido simultaneamente um novo patamar de realização. A pintura de paisagem conquistou seu lugar próprio no panorama da arte ocidental no século XVII, não por acaso o século de Descartes, quando a chamada subjetividade moderna ganhou uma elaboração mais nítida e expressiva. Ainda conforme Casey, a novidade de então não era propriamente o fascínio com as novas possibilidades de representação pictórica, cada vez mais acuradas - uma vez que os encantos da mimese já vinham se fazendo sentir desde o mundo grego, chegando ao Renascimento com o triunfo da perspectiva linear. A novidade propriamente moderna era "a conviç̧ão de que o mundo mesmo era como uma imagem". (CASEY, 2002, p.233)

O mundo concebido como imagem demanda ainda um outro fator além de um sujeito que o disponibilize para tal, traduzindo-o - ou melhor, espelhando-o - na arte e nos mapas, por exemplo. Mundo como imagem, no sentido de uma representação gráfica ou pictórica, demanda também aquilo que costumamos 
chamar de "moldura", ou "enquadramento", que pode ser compreendido literalmente, como no caso da pintura, ou num sentido bem menos inocente, como recortes ou "edições" de aspectos do mundo visível com a intenção de captura, ou de controle, de suas imagens. Casey, na obra citada, traz esta importante questão da moldura, ou do parergon, que ganhou uma tematização admirável pelas mãos de Jacques Derrida, e afirma:

Situada entre a superfície da pintura e a parede que a exibe, o enquadramento físico de uma pintura é um parergon, uma 'moldura' ('by-work') no sentido literal de existir na borda, como a borda. Como parergon - "em torno" (para) "obra" (ergon) - ela assume o status ambíguo ao qual a própria pintura de paisagem foi relegada na arte ocidental antes que seu interesse intrínseco fosse reconhecido. (...) Desta posição suplementar, o enquadramento físico assume vários papéis aparentemente contraditórios. (CASEY, 2002, p.122)

Tais papéis assumidos pelos enquadramentos próprios das pinturas de paisagem, por exemplo, ou daquelas em que visões do mundo físico se constituíam de alguma forma como temas, envolviam a prerrogativa de incluir ou de excluir, de enfatizar ou de marginalizar elementos das imagens que emolduravam. A criação de imagens pictóricas do mundo encontrou na ideia de enquadramento, ou moldura, um forte aliado. E, no caso específico da arte, se levarmos esta noção aos seus mais sutis desdobramentos, veremos que o próprio museu constitui um emolduramento ainda mais amplo, talvez ainda mais poderoso, no que diz respeito ao poder de legitimação de tais imagens. As paisagens do mundo, assim duplamente emolduradas, perpetuavam imagens, ou visões, que construíam a um só tempo qualquer concepção possível de "paisagem", o que era confirmado pela dimensão institucional da própria arte, ou, como se costuma dizer, do "mundo da arte".

A ideia de representação, que não encontrou resistências ao longo de séculos de produção artística, veio a ser profundamente questionada já nas primeiras décadas do século XX em diversas obras dos artistas das chamadas vanguardas históricas. A crise da representação, no âmbito das artes visuais, encontrou sua plena expressão já neste momento. Mas, no que diz respeito à paisagem propriamente, ou à possibilidade de sua representação pela arte, talvez o momento mais significativo desta crise tenha se traduzido nas obras de um grupo de artis- 
tas, em sua maioria americanos e ingleses, que nas décadas de 1960-70 deram início, no âmbito das artes, a uma nova forma de relação com a paisagem. Esta foi então deslocada não apenas para fora das galerias e dos museus, para fora das molduras e enquadramentos, mas igualmente para fora da representação, se assim podemos dizer. Nesta nova abordagem, que ficou conhecida como Land $A r t$, a relação dos artistas com o ambiente natural se deu de uma forma tal que a própria terra se tornou a matéria prima de suas obras. Não era a simples representação de paisagens que mobilizava estes artistas, mas, antes, o desejo de deixar nelas próprias, em sentido literal, a marca de sua arte.

A alusão à Land Art no contexto desta reflexão deve-se ao fato de que, nas obras reunidas sob esta rubrica, a proximidade entre o artista e o geógrafo parece se estreitar, e isso não apenas em função de um profundo interesse pela Terra mesma, mas também pelo freqüente uso de discursos, por parte de alguns artistas, que guardam uma surpreendente afinidade com aqueles do geógrafo, e não menos do geólogo. A identificação das obras da Land Art com seus sítios era completa.

Este profundo interesse pelo o lugar, pela própria paisagem, e, em última instância, pela Terra, os levou a lidar com novas circunstâncias e, principalmente, com a nova escala que suas obras assumiam. Dennis Oppenheim assim expressou estes desafios:

Uma boa parte de meu pensamento preliminar se dá vendo mapas topográficos e mapas aéreos, e depois coletando vários dados a respeito das informações meteorológicas. Depois levo tudo isso para o atelier terrestre [terrestrial studio]. (...) Algumas coisas interessantes acontecem durante este processo: há uma tendência a se ter ideias grandiosas quando se observa amplas áreas em mapas, depois se descobre que é difícil atingi-las, então se desenvolve uma árdua relação com a região. (FERREIRA e COTRIM, 2006, p.277)

Como o próprio artista expõe, a apropriação de dados bidimensionais, como curvas de nível inscritas em mapas, e sua transposição para localizações reais se constituiu como uma nova forma de relação da arte com a terra que parece revelar um contra movimento no que diz respeito à representação, como uma volta, a partir do mapa, à própria Terra, agora concebida como um "atelier terrestre", e mesmo como "matéria prima", como que resgatada de suas objetivações anteriores. 


\section{Mente e Terra}

Diversos escritos destes artistas deixam ver, por outro lado, que há neste mesmo discurso, próprio à Land Art de um modo geral, uma preocupação com o sentido das obras que se aproxima de uma forma muito instigante da fenomenologia e das considerações sobre o papel desempenhado pela mente que, em ultima instância, tocam no cerne da questão da representação aqui tratada. Neste sentido, um dos mais importantes nomes da Land Art, Robert Smithson nos fornece um farto material para reflexão a partir de seus textos e entrevistas. Para Smithson, seu trabalho não se tratava, de forma alguma, de um "movimento de volta à natureza", sendo sua arte, como ele mesmo a definiu, antes de tudo um ato de observação e uma atividade mental. As afinidades entre mente e terra ganham em Smithson uma elaboração única, e em profunda coerência com suas obras. Em seu escrito Uma sedimentação da mente: projetos de terra, publicado em 1968, a íntima e essencial conexão entre ambas é expressa na marcante abertura de seu texto, que diz:

A superfície da terra e as ficções da mente têm um modo de se desintegrar em regiões distintas da arte. Vários agentes, tanto ficcionais quanto reais, de alguma maneira trocam de lugar entre si - é impossível evitar o pensamento lamacento quando se trata de projetos de terra, ou daquilo que chamarei de "geologia abstrata". A mente e a terra se encontram num processo de permanente erosão: rios mentais derrubam encostas abstratas, ondas cerebrais desgastam rochedos de pensamento, ideias se decompõem em pedras de desconhecimento, e cristalizações conceituais desmoronam em resíduos arenosos de razão. Faculdades em amplo movimento se apresentam neste miasma geológico e se movem da maneira mais física possível. Embora este movimento seja aparentemente imóvel, ele arrebenta a paisagem da lógica sob os devaneios glaciais. Este fluxo lento torna consciente o turbilhão do pensamento. Colapsos, deslizamentos de escombros, avalanches, tudo isso acontece dentro dos limites fissurados do cérebro. O corpo todo é sugado para o sedimento cerebral, onde partículas e fragmentos se fazem conhecer como consciência sólida. Um mundo frágil e fraturado cerca o artista. Organizar esta confusão de corrosões em padrões, gradações e subdivisões é um processo estético que mal foi tocado. (FERREIRA e COTRIM, 2006, pp.182-183) 
A força poética do texto de Smithson não nos convida, decididamente, a uma "análise", em um sentido filosófico e rigoroso, de suas palavras. O que delas transborda chega a nós de uma forma fluida e quase visual: a possibilidade de desintegração tanto da terra quanto das ficções da mente; a qualidade lamacenta de um pensamento que não é seco nem líquido, mas uma mistura de ambos, quando se trata de uma geologia abstrata; as profundas afinidades entre os processos da mente e os movimentos da terra; a fragilidade das cristalizações conceituais, tão sujeitas a erosão, colapsos e desmoronamentos quanto os rochedos da paisagem terrestre. Os "limites fissurados do cérebro" expõem as brechas por onde pensamentos escapam e, num movimento aparentemente simultâneo, o sedimento sensível penetra. A expressão "consciência sólida" parece dar conta da inevitabilidade destes fluxos e da inseparabilidade entre mente e terra.

Este processo estético, "que mal foi tocado", segundo o artista, e que amalgama mente e terra, regiões conceituais essencialmente vinculadas a paisagens físicas, envolve ainda um outro fator - uma certa dimensão mítica que impregna suas criações. Talvez a mais expressiva das obras de Smithson, a Spiral Jetty (1969-70), uma espécie de península em espiral composta de terra, rocha, cristais de sal e algas, que avançava sobre a superfície do Great Salt Lake, no estado de Utah, nos Estados Unidos, é uma perfeita tradução desta situação. As palavras do próprio Smithson, ao descrever a primeira visão do lugar onde sua futura obra se instalaria, não deixa dúvidas quanto ao poder decisivo - e mesmo arrebatador - da própria paisagem no ato da criação da obra. Disse ele:

\begin{abstract}
Contemplando o local, ele reverberava para os horizontes sugerindo um ciclone imóvel, enquanto a luz bruxuleante fazia com que a paisagem inteira parecesse sacudir. Um terremoto dormente propagava-se por uma imensa circularidade. Desse espaço giratório surgiu a possibilidade da Spiral Jetty. Nenhuma ideia, conceito, sistema, estrutura ou abstração podiam sustentar-se diante a realidade daquela prova fenomenológica. (KRAUSS, 2001, p.336, tradução modificada)
\end{abstract}

Não restam dúvidas de que não se tratava de uma obra "sobre" paisagem, mas de uma paisagem percebida como quase-obra; como algo vivo e movente, em permanente processo, do qual a Spiral Jetty parece ter sido uma conseqüência natural. A presença de um sentido de circularidade que marca tanto a própria 
obra como o depoimento do artista é, para a teórica da arte Rosalind Krauss, resultado não apenas da circularidade natural do lago, mas também daquilo que ela chama sua "ambientação mitológica", referindo-se ao fato de que a existência mesma de um lago salgado interior foi tida, durante séculos, como uma "excentricidade da natureza". Um dos mitos criados para explicar tal fato era de que o lago estaria, desde sua origem, ligado ao Oceano Pacífico por um imenso curso d'água que teria gerado perigosos redemoinhos no lago. "Ao utilizar a forma da espiral para imitar o redemoinho mítico dos colonos, Smithson incorpora a existência do mito ao espaço da obra", afirma Krauss. (KRAUSS, 2001, p.341)

Tal incorporação do mito à obra talvez não se deva somente a relatos como estes, mas também a outros dois fatores geográficos: primeiramente, às longas distâncias a serem vencidas por aqueles que se aventurassem por regiões inóspitas em busca das obras. Em segundo lugar, os efeitos do tempo sobre estas, com sua duração condicionada pela exposição permanente às intempéries. Em geral, além dos registros fotográficos, é na memória que elas ganham vida. Mais uma vez a essencial relação entre os espaços da terra e a mente se evidencia. As palavras do artista brasileiro Vik Muniz expõem bem esta íntima conexão, quando ele diz:

As localizações remotas de quase toda a land art criaram um infinito espaço a ser preenchido pela imaginação e pela interpretação. (...) Embora muita gente conheça fotos da Spiral Jetty de Smithson, são pouquíssimas as pessoas que viram a coisa real. Smithson não construiu meramente uma forma numa remota lagoa em Salt Lake City, construiu um monumento em nossas mentes. (MUNIZ, 2007, pp.155-157)

\section{O Avesso da "Paisagem"}

Poderíamos considerar que os escritos de Smithson conferem uma outra dimensão às obras da Land Art, bem como lançam sementes muito férteis para a reflexão sobre a paisagem de uma forma mais ampla. De fato, o que ocorre em obras como a Spiral Jetty, por exemplo, é mais do que a simples quebra com a representação num nível meramente pictórico, mas trata-se, como Heidegger talvez o definisse, do acontecer de um espaço que então se faz visível, e isso de uma forma muito própria. É um espaço que acontece na tensão que se instala 
entre mente e matéria, ou no pensamento lamacento, como o definiu Smithson; numa geologia essencialmente poética que não é outra coisa senão o próprio aparecer do lugar, agora como paisagem em um sentido quase que avesso à sua acepção usual, ou seja, a de uma visão da "natureza" que se dá a um observador que se coloca diante dela e que a contempla "de fora", convertendo tal visão em uma imagem carregada de significados. Trata-se, antes, de uma relação com a Terra em que qualquer compreensão possível desta por parte do sujeito pode unicamente acontecer em seu ser situado, em sua absoluta inseparabilidade da terra, considerando-se aqui tanto a compreensão, pelo sujeito, de seu entorno, como a compreensão que possa ter de si próprio. A paisagem não se mostra, então, como que diante deste, mas envolvendo-o, abarcando-o e mesmo condicionando qualquer possível representação por parte dele. E assim nos aproximamos da fenomenologia de Heidegger que, afastando-se do foco tradicional na pura consciência de um sujeito, volta-se antes para o aparecer das coisas no âmago da existência mesma, para o processo de seu vir à luz na materialidade da vida.

A poesia implícita tanto às obras como aos escritos de Smithson parece dissolver qualquer possibilidade de separação ou de contraposição entre sujeito e mundo, ou, mais ainda, entre mente e terra, num sentido talvez mais radical do que à primeira vista possa parecer. Sua arte, como a de outros artistas da Land Art, parte da própria representação - de mapas e curvas de nível, por exemplo - para construir marcos terrestres que não existiam em tais mapas, e que neles jamais existirão, mesmo que sua ligação com estes mesmos mapas seja visceral. Ainda pensando em Heidegger, são "anti imagens de mundo", se assim podemos dizer, na medida em que recusam qualquer distanciamento da terra por parte do olhar, não podendo ser classificadas simplesmente como "intervenções na paisagem", ou "acidentes geográficos" artificiais. São antes, como diria o filósofo, o acontecer da verdade do lugar, de seu aparecer mais genuíno.

O jogo recíproco entre a materialidade do mundo e a compreensão que deste podemos ter, como nos mostra a arte, parece nos arrastar para esta luminosa tensão entre mente e matéria, entre mapa e território, pondo em risco a aparente inevitabilidade da representação e conduzindo-nos a uma espécie remota de poesia onde esta tensão encontra sua unidade e da qual retira sua força. Esta premissa parece encontrar eco, mais uma vez, nas palavras de Smithson:

Quando as fissuras entre mente e matéria se multiplicam em uma infinidade de lacunas, o ateliê começa a desabar, como na $A$ queda do solar de Usher, de modo que men- 
te e matéria se confundem interminavelmente. Sair do confinamento do ateliê liberta o artista, em certa medida, das armadilhas do ofício e da sujeição da criatividade. Tal condição existe sem qualquer apelo à "natureza". (FERREIRA e COTRIM, 2006, pp.191 - grifo do autor.)

O desabamento do ateliê, como a queda deste lugar próprio do artista, onde a alquimia da transmutação de território em "paisagem" em geral aconteceu, implica muito mais do que um simples sinal da saída física do artista do confinamento de seu laboratório. Implica, em última instância, que a fissura entre mente e matéria atinge uma intensidade tal que acaba por comprometer toda a estrutura anterior desta relação. Não devemos aqui compreender a palavra "fissura" apenas em seu sentido de ruptura, ou de separação. Antes, a fissura, ou a fenda, é justamente a abertura que permite a passagem de um âmbito a outro, é a possibilidade mesma de contaminação, de fusão, de mistura total. São precisamente as "fissuras entre mente e matéria", como diz Smithson, que possibilitam o pensamento lamacento, permitindo, ainda segundo suas palavras, que "a superfície da terra e as ficções da mente" possam, enfim, "se desintegrar em regiões distintas da arte", e talvez livres dos artifícios da representação.

É interessante observar a afirmação de que "tal condição existe sem qualquer apelo à "natureza"', esta última mencionada entre aspas. Trata-se de um importante indício de que o que está em pauta em uma obra como a de Smithson não é, em absoluto, um desejo nostálgico de volta à natureza, mesmo porque esta já se converteu, há muito, em "natureza", ou seja, em artifício. Pode-se perceber, além disso, que estas palavras reafirmam o caráter essencialmente mental da arte, caráter este que é plenamente assumido pelo artista. O que está em questão aqui não é exatamente a relação entre arte e paisagem, ou entre artista e natureza, mas uma relação talvez mais fundamental entre mente e terra, entre pensamento e matéria, em seu sentido mais arcaico e menos artificial: "o próprio cérebro assemelha-se a uma rocha que sofreu erosão, uma rocha da qual vazam ideias e ideais". (FERREIRA e COTRIM, 2006, pp.182-183) 


\section{Desertos}

A aparente impossibilidade de se pensar em termos de representação quando se considera a questão da paisagem veio sendo discutida até aqui, partindo de alguns temas de Heidegger, não especificamente concernentes a esta questão. A Land Art e, principalmente, os escritos de Robert Smithson foram abordados em seguida, como possíveis contrapontos à esta premissa, ou seja, a da inevitabilidade da representação, uma vez que as obras produzidas por Smithson e pelos artistas deste movimento tocam no âmago do problema - ainda que esta não tenha sido sua intenção explícita -, e estabelecem conexões com outras formas de representação da terra fora das artes, como as que são levadas a cabo pela geografia, por exemplo. Trata-se, na verdade, de uma discussão com inúmeros e complexos desdobramentos, e o que aqui se pretende é apenas sinalizar um dos (muitos) possíveis caminhos de abordagem, cuja riqueza não se deixará esgotar neste breve estudo. De fato, a questão que envolve paisagem e representação encontra nas obras e reflexões dos artistas ligados a este movimento elementos altamente expressivos de sua abrangência. Um destes elementos, que se poderia dizer essencial, é o isolamento. Para este convergem a solidão, o estranhamento e a perda de referências. No contexto de nossa cultura, talvez a melhor tradução "paisagística" para o isolamento seja o deserto, ambiente dos mais caros aos artistas da Land Art que fizeram da terra a matéria prima e a fonte dos temas de suas obras. As relações entre o deserto e a temática mais ampla que envolve a representação serão discutidas a seguir.

O deserto, mais do que qualquer outro local, se mostrou como o cenário ideal, aberto e, na medida do possível, não contaminado, para tais obras. "O isolamento é a essência da Land Art"' (GALOFARO, 2004, p.78), afirmou o artista americano Walter de Maria. A visita a certas obras, como já foi antes mencionado, exige que aqueles que desejam contemplá-las se desloquem para regiões longínquas, inóspitas e em geral não familiares; que se distanciem de suas referências geográficas e visuais, mergulhando numa paisagem que se impõe como "absolutamente outra”. Em seu estudo sobre a Land Art, Glória Ferreira afirma que:

As narrativas de deslocamentos têm sido incorporadas à descrição das obras. Com efeito, diversos visitantes falam em viagens e em travessias de diferentes regiões - como a costa oeste dos Estados Unidos - para chegar aos sítios da Land Art. O deslocamento pode tornar-se 
o próprio tema da narrativa e, portanto, da descrição da obra, na medida em que esta o incorpora enquanto elemento operatório, e que orientação e desorientação se fundem no âmago de seu funcionamento. (...) Se as condições de acesso são incorporadas à significação do trabalho, o tempo de viagem "onde não estamos em parte alguma" é inerente a seus dispositivos. O deslocamento geográfico tem uma relação com o percurso na obra: por exemplo, para se conquistar a paisagem, há que se perder nela. (FERREIRA, 2000, pp.185-187)

O fascínio dos desertos não limitou, contudo, a criação de importantes obras em centros urbanos ou em regiões rurais, onde o profundo estranhamento por elas provocado nas visões habituais, e mesmo banalizadas, de suas paisagens acabou por se tornar um de seus mais poderosos trunfos.

A alusão ao deserto no presente contexto - e não apenas ao deserto em sentido estrito, mas a qualquer paisagem marcada, principalmente, pelo isolamento e pela (quase) ausência de habitar humano - se faz indispensável não apenas a propósito destas obras artísticas, mas sobretudo em função da temática central deste estudo, que concerne à relação entre paisagem e representação. Seria uma ingenuidade tomarmos o deserto como um cenário "limpo" e "vazio", isento de conotações: sua imagem em nossas mentes é tão poderosa e pictórica que torna impossível, talvez, seu escape à densa malha dos lugares "construídos" pelo homem. E isso principalmente no que concerne aos desertos americanos, em torno dos quais uma complexa mitologia vem de longa data se constituindo, especialmente pelo cinema. O que aqui está em questão não é esta mitologia, e menos ainda o desejo de aprofundar o sentido "paisagístico" do deserto no vasto repertório de imagens do mundo forjadas pelo homem. O que se busca é, antes, uma compreensão do sentido assumido pelo deserto quando se considera a possibilidade de uma outra aproximação da terra pela arte do século XX, ou seja, o deserto como o lugar por excelência do encontro - encontro a um só tempo novo e arcaico - entre mente e terra para além da representação.

Este por em xeque o caráter aparentemente inevitável da representação quando se considera a noção de paisagem - a representação tanto por parte da arte, como por parte do pensamento, de um modo geral -, demanda certamente maiores explicações. Os tópicos que se seguem abordarão alguns aspectos do que poderíamos talvez chamar uma desconstrução do sentido moderno de 
paisagem, ou seja, do sentido que se construiu a partir do início da modernidade, o tempo da imagem do mundo, segundo Heidegger; imagem esta que teria na representação uma indispensável aliada. Não devemos perder de vista que a desconstrução mencionada não foi desencadeada exclusivamente no âmbito das artes e que o aspecto muito específico a ser aqui abordado - as obras da Land Art em sua relação com o deserto - não esgota em absoluto suas origens.

\title{
-1 -
}

Para Robert Smithson, "o deserto é menos 'natureza' do que conceito, um lugar que engole as fronteiras". Esta declaração expressa uma ideia bastante significativa: que uma paisagem (no caso, o deserto) é, por definição, um conceito, e já não mais "natureza". E isto porque quando chegamos a pensar e a falar em "paisagem", já estamos em um certo nível de "artifício" a partir do fato do território, se é que não podemos dizer o mesmo do termo "natureza". Deserto é antes um conceito que um lugar natural, em um sentido genuíno. É também "um lugar que engole fronteiras", e isto é o que nos interessa especialmente aqui. Se considerarmos fronteiras, neste contexto, como um equivalente da noção de enquadramento, podemos considerar, como afirma Malcolm Andrews, que este elemento é crucial para a definição mesma de paisagem. Ele diz:

\begin{abstract}
A paisagem adquire uma organização significativa como resultado de certos fatores extrínsecos e extrínsecos. Uma moldura estabelece os limites externos da vista; dá definição à paisagem. A moldura literalmente define a paisagem, tanto por determinar seus limites exteriores, como no sentido de que a paisagem é constituída por sua moldura: esta não seria uma paisagem sem aquela moldura. (ANDREWS, 1999, p.5)
\end{abstract}

$\mathrm{O}$ enquadramento, ou as fronteiras que delimitam e definem uma "paisagem", não são outra coisa senão a operação mental realizada pelo artista assim como faz o geógrafo, o paisagista, o poeta ou quem quer que produza "imagens" do mundo -; são representações, que não podem prescindir de tais limites. $\mathrm{O}$ deserto, como aquele que engole fronteiras, parece aqui assumir uma 
função, ou mesmo um poder, de dissolver as condições mais elementares para que aconteçam enquadramentos, a começar por aquele operado pela própria instituição artística, como foi antes mencionado, personificada pela sala branca e fechada, no museu ou na galeria. Não obstante, o próprio Smithson já declarara seu gosto pelos "limites artificiais que a galeria apresenta", domínio do qual sua arte não estaria de todo desligada. ${ }^{1} \mathrm{E}$ chegou mesmo a declarar que, do ponto de vista artístico, não se está mais livre no deserto do que dentro de uma sala. (FERREIRA, 2006, p.279) Poderíamos, talvez, considerar que a referência ao espaço fechado, próprio das galerias e museus, seja uma presença constante não apenas nas mentes dos artistas, mas na própria constituição do conceito moderno de arte: neste sentido, as obras sempre estarão em uma certa relação com estes espaços, ainda que seja para negá-los, ou recusá-los.

No que tange à questão aqui abordada, penso que estas declarações de Smithson não tornam menos poderosa a força do deserto e seu significado para a Land Art, e menos ainda para uma reflexão sobre a representação. Pois ainda que o sair para fora dos limites institucionais da arte possa não ser o fator preponderante nas motivações destes artistas em sua ida para o deserto, a busca de um contato com a terra num âmbito tão avesso aos enquadramentos sugere uma espécie de regresso à terra em um sentido anterior à própria ideia de "paisagem", sendo tal regresso o que há de mais significativo em termos de uma não representação da terra pelas obras deste movimento. Pois assim como engole fronteiras, o deserto também sobrepuja o homem, desafiando o exercício de seu poder dominador e objetificador, se assim podemos dizer.

\section{-2 -}

O colocar-se diante de um território e tomá-lo como objeto organizado e editado pela mente representadora do homem pressupõe, de antemão, a antiga separação entre o território efetivo, natural, e a obra de arte, em seu registro representacional e posterior ao próprio território, ou seja, em sua interpretação como "paisagem". O mesmo ocorre entre o território e o mapa. Tal distinção pode ser resumida em uma forma bem sucinta e direta: arte e natureza não são a

1Esta declaração pode ser encontrada em uma entrevista concedida à Avalanche, em 1970, intitulada "Discussions with Heizer, Oppenheim, Smithson". Uma tradução desta entrevista integra a coletânea Escritos de Artistas. Anos 60/70, organizada por Glória Ferreira e Cecília Cotrim, citada na bibliografia deste trabalho. 
mesma coisa. Se, por um lado, não podemos simplesmente negar a veracidade desta afirmação, por outro lado podemos, sim, recusar a dura oposição que nela é sugerida. O caráter aparentemente óbvio e irrecusável desta ideia se apóia, sem dúvida, na progressiva transformação do território em natureza e desta em imagens - muitas vezes pictóricas e artísticas - pela via da representação. Esta questão foi abordada por Andrews nos seguintes termos:

Uma 'paisagem', cultivada ou silvestre, já é um artifício antes mesmo de tornar-se tema de uma obra de arte. Ainda quando simplesmente olhamos, já estamos dando forma e interpretando. Uma paisagem pode nunca alcançar representação em uma pintura ou fotografia; contudo, algo de significativo terá acontecido quando o território (land) puder ser percebido como 'paisagem' (landscape). Podemos seguir um impulso de esboçar ou fotografar um traço particular de um território em uma vista, e chamar a imagem resultante de 'uma paisagem', mas não é a feitura formal de um registro artístico da vista que constituiu o território como paisagem. Caso sejamos ou não artistas, estamos sempre fazendo este tipo de conversão mental por séculos. O hábito é parte de toda a história de nossa relação com o ambiente físico, e a tradição visual da representação da paisagem foi desde o início um dos elementos vitais nesta relação. (...)

Imagens de paisagens também reproduzem preconceitos visuais que talvez nunca encontrem expressão formal em obras de arte, mas que são influências conformadoras cruciais em termos da forma pela qual nós particularmente respondemos tanto ao nosso ambiente natural, quanto às imagens deste ambiente. (ANDREWS, 1999, p.1)

Estas conversões consecutivas de território em paisagem e de paisagem em obra de arte apenas podem ser postas em risco quando a identidade entre território e obra se impõe, impossibilitando a operação representacional. A afirmação do artista Michael Heizer de que "o trabalho não é posto em um lugar, ele é esse lugar" (FERREIRA e COTRIM, 2006, p.275) aponta para o fato de que tal separação entre obra e território é passível de ser suprimida, tornando dispensáveis, e mesmo sem sentido, conceitos como os de enquadramento, recorte, fronteiras e relativizando, em última instância, a 
noção tradicional de paisagem. E ainda que seja justo afirmar que este fato não é uma exclusividade das obras nascidas do próprio deserto, ou dos lugares desabitados, é igualmente um fato que toda esta reflexão veio à luz a partir das condições oferecidas especificamente por tais lugares.

\section{- 3 -}

A propósito desta noção tradicional de paisagem - leia-se o conceito moderno de paisagem -, será interessante voltarmos ao sentido, ou aos sentidos, implícitos nesta palavra, paisagem. A esta é possível se associarem termos como sítio, vizinhança, um segmento do território que pode ser percebido como marcado por características próprias, ou mesmo "recortado" pelo olhar de um artista que o represente pictoricamente como formando uma unidade de sentido, do ponto de vista estético. Nas palavras de John Brinckerhoff Jackson, em sua obra Discovering the Vernacular Landscape, encontramos a seguinte definição:

Paisagem é um espaço na superfície da terra; intuitivamente sabemos que é um espaço com um grau de performance, com seu caráter próprio e distinto, tanto topográfico como cultural, e, acima de tudo, um espaço compartilhado por um grupo de pessoas; e quando vamos além da definição de dicionário para paisagem e examinamos a palavra mesma, constatamos que nossa intuição está correta. (JACKSON, 1984, p.5)

O autor, retomando definições mais antigas de paisagem, definições que remontam ao início da era moderna, registra que tradicionalmente paisagem é uma "porção do território que o olho pode abarcar com uma visada". (JACKSON, 1984, p.3) Jean-Marc Besse, em sua obra já citada, diz que:

A Landschaft é de início um lugar que se define por vizinhanças, humanas e naturais, que se pode designar como objetivas, e que podem assim ser cartografadas. Além da mera consideração de sua posição relativa, a Landschaft se define também por um conjunto de propriedades, na- 
turais e humanas, cujo inventário constitui sua qualidade ou sua natureza próprias. (BESSE, 2000, p.21)

Um dos traços mais marcantes que parecem ter acompanhado o sentido mesmo de paisagem desde o surgimento de sua concepção moderna é o seu caráter local, ou seja, delimitado por vizinhanças humanas, restrito àquilo que um relance de olhar pode apreender. Mas antes que este moderno conceito de paisagem se estabelecesse, antes que a pintura de paisagem fosse concebida como um gênero autônomo, antes que a paisagem, em si mesma, se tornasse um interesse para a geografia, em pinturas e mapas anteriores ao início da chamada modernidade as feições da terra e do mundo habitado já haviam atingido um alto grau de complexidade e beleza, mas nem sempre marcados por este caráter vernacular, local, facilmente compreendido em uma visada humana. Antes, o que veio a ser chamado de paisagem se integrava ao cosmos, às esferas celestes, ou seja, compreendia-se como parte de um todo muito mais amplo.

O deserto, onde as presenças do sol e do céu se fazem mais presentes e evidentes, convida a formas de arte que lidam não exatamente com o entorno concebido como "paisagem" no sentido acima descrito, mas antes com a Terra em uma dimensão que se poderia dizer cósmica, que parece reestabelecer contato com pinturas pré-renascentistas que apresentavam o ambiente humano e as esferas celestes em um único e mesmo todo. ${ }^{2}$ Resgata-se aí o sentido de "mundo" como o âmbito mais amplo e abrangente, o sentido que tinha para os antigos: o universo, como o que não se deixa objetivar, o irrepresentável, se assim podemos dizer. Neste sentido, o "mundo" que se faz presente em algumas das obras da Land Art em muito se afasta das representações do céu dentro dos limites de enquadramento das pinturas de paisagem, de um modo geral.

A título de exemplo, duas destas obras, ambas realizadas nos Estados Unidos, que evocam de maneira visceral o que Heidegger chamaria o co-pertencimento da terra e do céu, devem ser mencionadas aqui. A primeira delas é a monumental Sun Tunnels, de Nancy Holt, que não se limita a esta primeira relação - entre terra e céu -, mas evoca também a imbricação espaço-tempo de uma forma que escapa a toda e qualquer abordagem abstratizante, ou representacional, destes. The Lightning Field, de Walter de Maria, será a segunda das duas obras que guiarão esta reflexão.

2Será interessante lembrar que este tipo de interpretação totalizadora é anterior ao início da chamada modernidade, quando os âmbitos da arte, da ciência e da religião, embora não de todo separados, começaram a delimitar seus domínios específicos. 
Sun Tunnels (Utah, 1973-6) se configura a partir de quatro túneis em forma de cilindros de cimento, contendo diversas perfurações circulares, dispostos no solo do deserto em forma de cruz. Esta disposição nada tem de casual: exatamente como estão posicionados em relação ao sol, os tubos perfurados marcam o ciclo de um ano solar. ${ }^{3}$ Em entrevista a Laura McLean-Ferris, Holt expõe os desejos e intenções que nortearam seu trabalho. Ela diz:

Nosso sol é uma estrela no universo, lançando sua luz através dos buracos-estrela [star-holes] nas metades superiores dos Sun Tunnels, produzindo na parte mais baixa dos túneis pontos de luz que a todo momento se modificam. Somente quando o sol está diretamente sobre um buraco, um círculo pleno de luz é lançado, permanecendo o resto como elipses pontiagudas (mandorlas) e moedas de luz [silvers of light]. Você caminha através dos túneis ao meio dia e está caminhando nas estrelas sol/ luz das estrelas, lançadas na forma de uma constelação a seus pés. Escolher que constelações de estrelas foi uma decisão estética. Testei inúmeros desenhos diferentes de constelações usando diferentes mapas estrelares. Se você começar a olhar mapas de estrelas verá que ao longo dos anos, dependendo da época e de quem fez o mapa, haverá diferentes estrelas incluídas ou excluídas em um certo arranjo de estrelas chamado constelação.

Descobri isso quando realizei minha obra Hydra's Head, junto ao Rio Niagara, em 1974. Depois, quando fui a Utah no ano seguinte, comecei a trabalhar com diferentes constelações, tentando decidir quais delas eu queria para os Sun Tunnels. Deveria haver estrelas suficientes, de diferentes magnitudes, uma vez que os diâmetros dos buracos mudavam de acordo com a magnitude das estrelas, e a constelação precisaria se estender em torno da

3 Luca Galofaro, em sua obra Artscapes, nos oferece uma descrição desta obra: Sun Tunnels é uma obra capaz de indicar e medir o ciclo temporal de um ano solar. A escultura está formada por quatro tubos de cimento colocados em X e alinhados com o ângulo em que o sol nasce e se põe nos dias do solstício de verão e de inverno. Nestes dias, o sol fica perfeitamente alinhado com o centro dos túneis e durante o verão este alinhamento se mantém durante alguns dias. Na superficie da cada tubo há perfurações de diferentes diâmetros, em função da magnitude das estrelas que estes representam. Cada série de furos representa uma constelação. A luz do sol produz diferentes efeitos nas diferentes horas do dia, projetando nas paredes internas dos cilindros figuras que se modificam constantemente". 
metade superior de um cilindro, de uma forma que fosse interessante e que deixasse alguns buracos ao nível dos olhos, de forma que você pudesse olhar através deles. ${ }^{4}$

As palavras de Holt confirmam algumas ideias tratadas aqui anteriormente. O sol participa efetivamente de um obra que o tem como "tema". Mais do que isso, é ele quem desenha, literalmente, a parte mais decisiva, pondo-se em relação direta tanto com as constelações de estrelas como com os cilindros de cimento sobre o solo do deserto. O observador da obra é convidado a penetrá-la e a andar sobre estas constelações, em uma caminhada que o conduz a elas a partir do deserto. O uso do mapa estrelar, em um movimento que parte deste para a realização de uma obra concreta, em muito lembra o modus operandi de outros artistas da Land Art. Mas a decisão, como a própria artista diz, é de ordem estética, lúdica, visando apenas mostrar como um poema feito de cimento e terra ainda se remete, mas de forma livre, a esta antiga forma de representação do espaço cósmico que é o mapa das constelações. A maneira como Nancy Holt se refere, de um modo tão natural, à necessidade de "estrelas suficientes" para a confecção de sua obra aponta indiscutivelmente para o fato de que os materiais tradicionais já não eram necessários.

Em outra passagem significativa Holt deixa ver como um agudo sentido de paisagem perpassa suas intenções ao conceber esta obra. Diz a artista:

Quis devolver à escala humana o vasto espaço do deserto. Não era meu desejo fazer um monumento megalítico. A vista panorâmica da paisagem é arrebatadora demais para ser apreendida sem pontos visuais de referência. A vista se embaça mais do que se aguça. Quando nos encontramos no centro da obra, os túneis atraem nossa visão para a paisagem, revelando o espaço percebido. Mas uma vez dentro de um dos túneis, a obra nos encerra e nos envolve, e a paisagem é emoldurada pelas aberturas dos túneis e pelos buracos de estrela. ${ }^{5}$

4 Nancy Holt em entrevista a Laura McLean-Ferris em Art Review, setembro de 2012, número $61, \mathrm{p} .81$.

5 KASTNER, Jeffrey e WALLIS, Brian. Land and Environmental Art. Londres: Phaidon Press, 2005, p. 228 . 
Aqui, a presença humana diante da imensidão do panorama que se desenrola; a necessidade, igualmente humana, de criar marcos que tragam alguma definição e referência a esta vastidão - a disposição em $\mathrm{X}$ dos cilindros como um traçado de registro no solo -; a obra como a própria tradução material do estar aqui humano e, finalmente, o ato de emoldurar a paisagem, terrena ou celeste, para que nossa apreensão dela possa acontecer.

Mas o encontro do céu e da terra pode, por outro lado, evocar a violência potencial dessa relação, exposta em toda a sua força e beleza na solidão dos lugares desabitados. Quando a natureza escapa a todo controle humano, o sentido mais genuíno de "paisagem" parece escapar também. Dissolvem-se as formas, desfazem-se as visadas e enquadramentos; qualquer sentido de estabilidade, ou de "composição", se perde. Tal é a condição com que se defronta o impressionante The Lightning Field (Novo México, 1977), de Walter de Maria, obra em que a centralidade da relação entre o céu e a terra foi por ele explicitamente afirmada. Após cinco anos de busca pelo local mais apropriado, um território plano, com uma alta incidência de relâmpagos e marcado pelo isolamento, como informa o próprio artista em um escrito sobre a obra, onde ainda declara: "O terreno não é o cenário para a obra, mas uma parte da obra". ${ }^{6}$

The Lightning Field é formado por um conjunto de 400 postes pontiagudos de aço polido, dispostos regularmente no imenso platô, cujos limites podem ser percorridos em uma caminhada de aproximadamente duas horas. Os postes não permanecem visíveis, em sue conjunto, por todo o tempo: apenas noventa por cento se deixam ver a cada vez; aparecem e desaparecem conforme o ângulo em que o sol incida sobre eles, como se estes respondessem, em um diálogo silencioso, aos estímulos do céu. A presença de relâmpagos, durante sessenta dias por ano, gera intensos campos elétricos no ar, levando à ocorrência de um fenômeno conhecido como "fogo de São Telmo", que leva as pontas dos postes a transmitir luz uns para os outros, em uma espécie de rede luminosa ultra efêmera, e não menos impressionante.

"O invisivel é real". "Esta pequena frase de Walter de Maria, que aparece sozinha em seu texto já mencionado sobre The Lightning Field, aponta para um aspecto crucial de sua obra: o real é mais complexo, mais estranho e inacessível do que se supõe. Como observa Luca Galofaro, a obra de Walter de Maria

6DE MARIA, Walter. "The Lightning Field (1980). Some Facts, Notes, Data, Information, Statistics, and Statements", in STILES, Kristine e SELZ, Peter (Ed.). Theories and Documents of Contemporary Art - A Sourcebook of Artist's Writings. Berkeley: University of California Presss, 1996, p.527.

7 Ibid., p.530. 
"revela a paisagem invisível", fazendo visível o invisível da natureza. (GALOFARO, 2004, p.81) A dimensão de invisibilidade e a efemeridade do fenômeno elétrico, inerentes à própria obra, não a tornam, contudo, impermanente. Em sua silenciosa imobilidade, os postes brilham e resistem à violência das intempéries e repetem, ano após ano, quase ritualisticamente, a tarefa de tornar visível a beleza inerente aos jogos de luz dos relâmpagos na solidão do deserto.

Uma certa medida de solidão é outro ingrediente fundamental, confirmando, como já foi mencionado anteriormente, que "o isolamento é a essência da Land Art". Parte do conteúdo essencial da obra, como afirma de Maria, depende da proporção, ou razão, que se estabelece entre as dimensões do local e a quantidade de seus observadores: deve haver "um pequeno número de pessoas para uma grande quantidade de espaço". Preferencialmente a obra deve ser contemplada na solidão, ou por grupos muito reduzidos, daqueles que se dispuseram a enfrentar a longa viagem que a obra demanda. ${ }^{8}$

A solidão do deserto tem sido miticamente interpretada como a solidão própria ao encontro de alguém consigo mesmo, encontro onde dilemas atingem seu limite, onde os opostos se faceiam e se reconhecem como o mesmo. O encontro torna-se reencontro. Talvez pudéssemos dizer que apenas na solidão agreste do deserto tenha sido possível o reatar-se do encontro arcaico entre mente e terra, da arte consigo mesma, para além de qualquer interferência representacional, pois que anterior a toda possibilidade desta.

Poderíamos ainda considerar que se a ideia de paisagem já implica, para sua definição, a representação como fator estruturador, então uma arte que negue a representação, que lide com uma espécie de "matéria prima" da própria paisagem - no sentido de algo anterior a este mesmo conceito -, estaria minando, em certo sentido, o premissa da paisagem como sendo, inevitavelmente, representação. Ou, colocando em outros termos, estaria trazendo à luz uma saudável tensão no interior deste conceito: desestabilizando-o, no melhor sentido da palavra.

8Ibid., p.529. 
ANDREWS, Malcolm. Landscape and Western Art. Oxford: Oxford University Press, 1999.

BESSE, Jean-Marc. Ver a terra: seis ensaios sobre a paisagem e a geografia. São Paulo: Editora Perspectiva, 2006.

BOSI, Alfredo. A fenomenologia do olhar, em O Olhar, organização de Adauto Novaes. São Paulo: Companhia das Letras, 2003.

CASEY, Edward. Earth-Mapping: Artists Reshaping Landscape. Minneapolis: University of Minnesota Press, 2006.

Representing Place: Landscape Painting \& Maps. Minneapolis: University of Minnesota Press, 2002.

Getting Back into Place: Toward a Re-

newed Understandig of Place-World. Indianapolis: Indiana University Press, 1993.

FERREIRA, Glória. “Land Art: Paisagem como meio da obra de arte", in Paisagem e Arte, organizado por Heliana Angotti Salgueiro. São Paulo: Comitê Brasileiro de História da Arte, 2000.

. e COTRIM, Cecilia (orgs.). Escritos de Artistas. Anos 60/70. Rio de Janeiro: Jorge Zahar Editor, 2006.

GALOFARO, Luca. Artscapes: el arte como aproximación al paisage contemporâneo. Barcelona: Editorial Gustavo Gili, 2004.

HEIDEGGER, Martin. Caminhos de Floresta. Lisboa: Fundação Calouste Gulbenkian, 1998.

KASTNER, Jeffrey e WALLIS, Brian. Land and Environmental Art. Londres: Phaidon Press, 2005.

KRAUSS, Rosalind - Caminhos da escultura moderna, tradução de Julio Fischer. São Paulo: Livraria Martins Fontes Editora, 2001.

MUNIZ, Vik. Reflex. Vik Muniz de A a Z. São Paulo:
Cosacnaify, 2007.

PONTE, Alessandra. "The House of the Light and Entropy. Inhabiting the America Desert', in Paisagem e Arte, organizado por Heliana Angotti Salgueiro. São Paulo: Comitê Brasileiro de História da Arte, 2000.

SMITHSON, Robert. The Collected Writings. Editado por Jack Flam. Berkeley: University of California Press, 1996.

STILES, Kristine e SELZ, Peter (Ed.). Theories and Documents of Contemporary Art - A Sourcebook of Artist's Writings. Berkeley: University of California Presss, 1996. 